\title{
O contexto global e nacional frente aos desafios do acesso adequado à água para consumo humano
}

\author{
The global and national context regarding the challenges involved \\ in ensuring adequate access to water for human consumption
}

Lia Giraldo da Silva Augusto ${ }^{1}$

Idê Gomes Dantas Gurgel ${ }^{1}$

Henrique Fernandes Câmara Neto ${ }^{1}$

Carlos Henrique de Melo ${ }^{2}$

André Monteiro Costa ${ }^{1}$

${ }^{1}$ Departamento Centro de Pesquisas Aggeu

Magalhães, Fiocruz (PE) Av.

Moraes Rego s/n, Cidade

Universitária. 50.670-420

Recife PE.

giraldo@cpqam.fiocruz.br

${ }^{2}$ Superintendência Estadual

de Minas Gerais, Funasa,

Ministério da Saúde

\begin{abstract}
The scope of this article is to analyze the challenges involved in ensuring access to water for human consumption taking the international and national context into consideration. Based on the UN declaration that access to safe and clean drinking water is a fundamental human right, vulnerabilities are identified that can consist in restrictions to access to adequate supplies. The distribution of water and the population across the planet, pollution, inadequate policies and management lead to environmental injustice. The iniquity of access to water constitutes the contemporary water crisis. From the 1980s onwards, the transnational water market emerged for private control that occurs at three main levels: surface and underground water sources; bottled water; and public water supply services. The conflicts of the multiple uses of water resources, the market and environmental problems have contributed to rendering the health of the population and ecosystems vulnerable. Adequate public policies are essential to ensure the basic human right to access to safe and clean drinking water.
\end{abstract}

Key words Water, Access, Environmental justice, Human rights, Vulnerability, Protection of Water Sources
Resumo Este artigo tem como objetivo analisar os desafios do acesso à água para consumo humano, considerando-se o contexto internacional e nacional. A partir da deliberação da ONU de que o acesso à água limpa e segura é um direito fundamental de todo ser humano são identificadas vulnerabilidades que podem se constituir em restrições ao acesso. A distribuição da água e das populações no planeta, a poluição, as políticas e gestões inadequadas produzem injustiça ambiental. A iniquidade de acesso a água constitui-se na crise contemporânea da água. A partir da década de 1980, emerge o mercado transnacional de água pelo controle privado que ocorre em três níveis principais: de mananciais superficiais e subterrâneos; de água engarrafada; e dos serviços públicos de abastecimento. Os conflitos dos usos múltiplos dos recursos hídricos, do mercado e dos problemas ambientais têm contribuído para a vulnerabilização da saúde das populações e dos ecossistemas. São necessárias politicas públicas adequadas ao exercício do direito humano fundamental de acesso a água com qualidade.

Palavras-chave Água, Acesso, Justiça ambiental, Direitos humanos, Vulnerabilidade, Proteção de mananciais 


\section{Água para a saúde, as contradições e as perspectivas da política nacional}

Sobre a importância da água para a saúde e para a vida no planeta se sabe muitíssimo. Que é um componente imprescindível para os ecossistemas também não há dúvidas. A sobreposição de mapas com diversos indicadores de desigualdades sociais em contraste com indicadores de acesso e de qualidade da água revelam uma forte congruência entre eles. Observação esta que não constitui em novidade, assim como o reconhecimento global do papel decisivo da água no desencadeamento direto e indireto de uma grande quantidade de patologias; e no condicionamento da mortalidade geral e em especial a infantil, na grande maioria dos países em desenvolvimento.

No entanto, o despertar da água como um direito humano fundamental e a preocupação com a edição de legislações para salvaguardar a qualidade e o acesso a esse elemento natural, mediante políticas públicas, são questões recentes. Uma grande diversidade de órgãos legisla sobre a água no Brasil, inclusive uma Agência Nacional das Águas foi criada no ano 2000.

$\mathrm{Na}$ direção dos direitos humanos, Henrique Rattner $^{1}$ nos coloca um quadro de crise da água e apresenta algumas estimativas preocupantes: A proporção de pessoas vivendo em países que sofrem cronicamente de escassez de água, que chegava a 8\% (500 milhões) na virada do século, deverá subir para 45\% (quatro bilhões) em 2050.(...) Mesmo atualmente, um bilhão de pessoas se deita com fome por causa de falta de água para cultivar seus alimentos. Os habitantes de regiões de climas temperados, onde chuvas moderadas caem durante todo o ano, não conseguem perceber até que ponto a água é necessária para a agricultura. Na GrãBretanha, por exemplo, a atividade agrícola requer somente 3\% do consumo da água. Nos Estados Unidos, ao contrário, $41 \%$ de toda a água são consumidas pela agricultura, principalmente na irrigação. Na China, a agricultura absorve $70 \%$ e na Índia, quase $70 \%$ de toda a água. No mundo como um todo, o consumo pela agricultura chega a $70 \%$ do total. A demanda crescente por água da agricultura é causada não somente pelo maior número de pessoas a serem alimentadas, mas também pelo desejo destas de comer alimentos mais saborosos. É necessário o dobro de água para produzir amendoim do que para a mesma quantidade de soja; quatro vezes mais para produzir carne bovina, em comparação com a mesma quantidade de frango e cinco vezes para produzir um copo de suco de laranja do que um de chá. Com dois bilhões de pessoas a ingressarem na classe média, a demanda da agricultura por água irá subir, mesmo com a população permanecendo estável.

Agrega-se a estas questões o fato do Brasil ser o maior depositário natural de águas doces do planeta e ter por isto uma responsabilidade que é maior do que sua própria fronteira. Mas, onde quer que estejamos, no território nacional, nos deparamos com graves problemas sociais relacionados com a água, que vai desde situações de carência absoluta até o desperdício franco; passando por problemas de baixa qualidade por contaminação orgânica e química.

Questões de ordem ética estão no cotidiano de grande parte das comunidades quando, em um mesmo território, vemos uns terem água em quantidade e qualidade suficientes e para muitos ser esta inacessível ${ }^{2}$. Inclui-se entre essas iniquidades, o privilégio da oferta de água para empreendimentos de duvidoso interesse social. No agronegócio alguns exemplos são: os que usam a irrigação intensiva em regiões semiáridas; a monocultura de eucalipto; o avanço da soja no cerrado e na floresta amazônica, desmatando e eliminando nascentes; e a utilização de agrotóxicos em áreas próximas de mananciais. Na indústria, o exemplo da utilização de água para a produção de alumínio e de aço, que são processos energéticos intensivos que exigem a construção de barragens para usinas hidroelétricas, como a de Belo Monte do Estado do Pará, em detrimento dos povos tradicionais das florestas, bem como da biodiversidade e dos demais recursos naturais. Em geral, trata-se de empreendimentos subsidiados com recursos públicos e que não internalizam os custos sociais e ambientais deles decorrentes.

Como fazer cumprir o direito à saúde se a água com qualidade está muito distante da maioria da população? Uma profunda reforma no pensamento político do país é necessária, mediante construção de um pacto social que supere o utilitarismo e o pragmatismo vigentes. Para tal se requer: um pensamento ecossistêmico que supere a enorme fragmentação existente nas ações governamentais relativas à água, assim como para o desenvolvimento; e um radical compromisso com a sustentabilidade, fazendo cumprir a Constituição Federal, a Agenda 21, bem como os demais acordos de direitos humanos, sociais, culturais e ambientais assinados.

Em razão de sua capilaridade institucional e de suas múltiplas interfaces, a política de saúde deve estar presente junto às demais que tratam do desenvolvimento do país, com uma profunda revisão de suas práticas sanitárias dominan- 
tes que também sofrem do mal da fragmentação e da visão causalista linear.

A vigilância em saúde ambiental poderia ser um lócus privilegiado para esse repensar a crise crônica da água e do saneamento ambiental de modo geral, desde que se constitua em uma estratégia para um processo de mudanças, com ampla mobilização social, com apoio institucional e mediante políticas integradas nos três níveis de governo.

\section{Contexto político territorial da crise desigual da água}

A água em nosso planeta apresenta um volume praticamente constante. A água doce, utilizada com maior facilidade para consumo humano, é um bem natural renovável, apresentando variações de volume com as mudanças climáticas, pois esta armazenada em reservatórios superficiais e subterrâneos e nas áreas glaciais ficou acumulada em grandes geleiras. Existem variações sazonais que alteram a distribuição entre suas diversas formas ao longo do regime hídrico. Impactos ambientais, como desmatamentos têm alterado a disponibilidade de água, dificultando o uso para consumo humano. Atualmente, a água doce está distribuída de forma desigual no planeta, tanto entre os tipos de mananciais, como entre as regiões e intraregionalmente. Apenas $0,3 \%$ da água doce estão em mananciais superficiais e cerca de $30 \%$ no subsolo, e a maior parte, cerca de 70\%, está em geleiras.

A disponibilidade maior de água pode não garantir a efetiva distribuição equânime para populações humanas. A desigualdade da distribuição dos recursos hídricos contrasta com as diferenças populacionais. A Ásia, o continente mais populoso, concentra $59,8 \%$ dos habitantes e 31,6\% da disponibilidade total de água doce superficial do planeta. Por outro lado, as Américas contam com $13,6 \%$ da população mundial e $41 \%$ da água disponível (Tabela 1).
Mas há também desigualdades intracontinentais e num mesmo país. Um exemplo é o Brasil, que tem 2,8\% da população mundial e $12 \%$ da água doce do planeta. No entanto, 70\% dessa água estão na Bacia Amazônica onde a densidade populacional é a menor do país (Tabela 2). Por outro lado, a região mais árida e pobre do Brasil, o Nordeste, onde vive cerca de 30\% da população, possui somente $5 \%$ da água doce. A alta densidade populacional, a poluição, a agricultura, a indústria energético-intensiva e o desmatamento provocam o aumento na escassez de água de qualidade. Nas regiões Sul e Sudeste do país, onde vive cerca de $60 \%$ da população dispõe de $12,5 \%$ de água doce.

Faz-se necessário compreender melhor a relação entre a disponibilidade de água doce e a sua distribuição para consumo humano. As crises geradas pela escassez de água necessitam ser bem caracterizadas para não alimentar os interesses das grandes corporações sustentadas por entidades e organismos que querem privatizar os recursos hídricos ${ }^{5}$.

A água é o compartimento ambiental mais diretamente afetado pelas mudanças climáticas, aumentando a vulnerabilidade de territórios e populações, a exemplo do estresse hídrico de áreas já degradadas ${ }^{6}$. Os impactos ambientais

Tabela 2. Distribuição dos recursos hídricos e populacionais no Brasil por Região

\begin{tabular}{lcc}
\hline \multicolumn{1}{c}{ Região } & $\begin{array}{c}\text { Percentual da } \\
\text { disponibilidade hídrica }\end{array}$ & $\begin{array}{c}\text { Percentual da } \\
\text { população }\end{array}$ \\
\hline Norte & $68,5 \%$ & $6,8 \%$ \\
Nordeste & $3,3 \%$ & $28,9 \%$ \\
Sudeste & $6,0 \%$ & $42,7 \%$ \\
Sul & $6,5 \%$ & $15,1 \%$ \\
Centro-Oeste & $15,7 \%$ & $6,4 \%$ \\
Total & $100,0 \%$ & $100,0 \%$ \\
\hline
\end{tabular}

Fonte: Câmara ${ }^{4}$

Tabela 1. Distribuição percentual dos recursos hídricos e populacionais no Mundo por continentes.

\begin{tabular}{lcc}
\hline \multicolumn{1}{c}{ Continentes } & $\begin{array}{c}\text { Percentual da } \\
\text { população mundial }\end{array}$ & $\begin{array}{c}\text { Percentual da quantidade de água } \\
\text { superficial disponível }\end{array}$ \\
\hline África & $15,0 \%$ & $10,0 \%$ \\
Américas & $13,6 \%$ & $41,0 \%$ \\
Asia & $59,8 \%$ & $31,6 \%$ \\
Europa & $10,9 \%$ & $7,0 \%$ \\
Oceania/Austrália/Antártida & $0,5 \%$ & $10,3 \%$ \\
\hline
\end{tabular}

Fonte: Silva ${ }^{3}$ 
relacionados aos poluentes (dejetos humanos, lixo, venenos, efluentes agrícolas e industriais) e uso intensivo do solo para o modelo agrícola oriundo da Revolução Verde (dependência química e de biotecnologia, mecanização, irrigação, monocultura e concentração de terras) afetam negativamente a disponibilidade de água para consumo humano. Esta situação se agrava pelos desmatamentos e pela desertificação derivada da degradação das terras em zonas áridas, semiáridas e sub-húmidas secas ${ }^{7}$.

A superexploração de aquíferos subterrâneos acentua a escassez de água. A capacidade de sua recarga fica comprometida por um grande período de tempo. Outras adversidades advindas dessa insustentabilidade podem ocorrer, tais como: a contaminação e a salinização de águas subterrâneas oriundas de aquíferos superficiais degradados; drenagem de rios; subsidência de terrenos; e o aumento dos custos de bombeamento.

A gestão dos recursos hídricos assume grande importância porque afeta quase todos os aspectos da economia, segundo Castro e Scariot ${ }^{8}$, em particular: a produção de alimentos, saúde, segurança do abastecimento doméstico de água, esgotamento sanitário, indústria, energia e sustentabilidade ambiental. As privatizações dos recursos hídricos por grandes conglomerados econômicos e industriais, por exemplo, afetam o acesso aos mananciais de interesse para o consumo humano?.

Restrições de acesso podem advir da privatização dos serviços e também dos mananciais. A partir da década de 1980, este processo foi induzido pelo Banco Mundial, Banco Interamericano de Desenvolvimento e as agências multilaterais. Esse mercado da água é crescente e em 2003 era estimado em um trilhão de dólares pelo Banco Mundial $^{9}$. Duas empresas francesas, a Veolia e a Suez, detêm cerca de $70 \%$ do mercado, o que caracteriza um cartel da água. Os objetos de privatização, em geral, podem ser serviços integrais de água e esgotos ou plantas de tratamento de água e esgotos. E o mecanismo de gestão mais adotado atualmente tem sido a Parceria Pública Privada (PPP) que é praticada na Europa há mais tempo e que o Banco Mundial difundiu para os países em desenvolvimento. A PPP é um tipo de privatização em que os ativos não são vendidos, mas ocorre a concessão de serviços por um determinado período, na qual é definida e garantida a margem de lucro por contrato.

A partir da década de 1990, grandes corporações empresariais privadas têm ampliado sua dominação sobre mananciais de água doce, vis- lumbrando assim um mercado mundial de água, quer utilizando navios, bolsas gigantes puxadas por rebocadores, canais ou aquedutos para grandes demandas e distâncias, quer para o mercado de água engarrafada. Para esta última, observase que gigantes da indústria alimentícia como a Nestlé, Coca-Cola, PepsiCo., Procter \& Gamble e Danone já operam nesse mercado da água engarrafada. Mediante publicidade, indução de demanda de água segurança, baixo valor agregado estão obtendo altíssimos lucros. No Brasil, em resposta a pressão empresarial foi legalizado para o comércio um tipo de água engarrafada, não mineral, de qualquer captação, adicionada de sais minerais, por meio da Resolução 309/1999, da Anvisa $^{10}$.

A ONU estabelece que os direitos humanos sejam garantidos por normas internacionais, que asseguram as liberdades, os direitos fundamentais e a dignidade de indivíduos e comunidades. O direito à água está assim estabelecido: os Estados devem respeitar (gozo do direito à água), proteger (impedindo que terceiros, como as corporações, interfiram no gozo ao direito à água) e cumprir (adotando as medidas necessárias para alcançar a plena realização do direito à água ${ }^{11}$.

Paradoxalmente, mais de 80 países signatários, foram representados por seus Ministros do Meio Ambiente no Fórum Mundial da Água em março de 2012, na França, e assinaram a Declaração Ministerial de Marselha, que apresenta outra orientação, está sobrepondo os interesses econômicos aqueles dos direitos humanos a água, colando-a como commodities, ao possibilitar a integração do comércio de água em mercados de futuros e criar derivados no sistema financeiro ${ }^{12}$. Dentro do novo conceito de "economia verde" esta tendência vem camuflada. Trata-se da construção de uma nova agenda pela criação de um mercado especulativo para as corporações e instituições econômicas indutoras dessa estratégia. Para Barlow e Clarke ${ }^{9}$ A falácia inerente a este modelo [de privatização] é que ele é inevitavelmente não-sustentável; ele exige consumo crescente enquanto contribui com muito pouco para a conservação dos recursos.

A relatora especial das Nações Unidas para o direito à água e saneamento, Catarina de Albuquerque, critica o documento de Marselha, ao apontar o relativismo da linguagem e o enfraquecimento desse direito. Sua preocupação com a Rio+20 é repetir, com a crise da água, a especulação diante da crise alimentar global, que provocou lucros nas bolsas de valores para empresas alimentícias ${ }^{13}$. 
Cabe lembrar que o Fórum Mundial da Água foi organizado pelo Conselho Mundial da Água, que é presidido pela empresa Suez Environment, uma das maiores transnacionais do mundo no mercado da água. A declaração de Marselha tem influenciado o Conselho de Direitos Humanos da ONU no contexto que antecede a Rio +20 , causando impacto institucional, pelo processo de privatização dos recursos hídricos e/ou dos serviços de água ${ }^{12}$.

Esse contexto é de iniquidade de poderes entre os governos locais, a sociedade e as corporações privadas. O retrocesso do direito à água provocado pela privatização desse setor tem acelerado a exclusão social. Mais de um bilhão de pessoas consome água inadequada. Atualmente 20 países vivem em escassez crônica de água. O World Water Development Report de 2003, da UNESCO-WWAP, estima que em 2050 um quarto da população do planeta viverá em situação de escassez crônica de água potável ${ }^{14}$. No Brasil, somente um terço dos $40 \%$ mais pobres dispõem de serviços de água e saneamento, enquanto que para os $10 \%$ mais ricos esse valor sobe para $80 \%$.

No Brasil, além de baixa capacidade de reivindicação da sociedade, sobretudo em relação ao saneamento, as agências de regulação desse setor são incipientes, com raríssimas exceções, onde poucos municípios são efetivamente regulados. E esta regulação é basicamente tarifária.

A privatização, além do jogo de interesses econômicos e políticos, produzem uma assimetria de poder, comprometendo também, além de o direito à água, o acesso à informação de dados necessários para a gestão pública exercer o seu dever de estado para com a sociedade.

\section{Água como direito humano, justiça ambiental e ética}

A crise da água tem sido objeto de grandes debates, análises, relatórios e resoluções pelas agências internacionais. No Quadro 1 apresenta-se uma síntese das principais considerações apontadas no Relatório de Desenvolvimento Humano (RDH - 2006) ${ }^{15}$, no documento "Pôr fim à crise no sector da água e do saneamento básico", agregado de reflexões dos autores.

Todas essas considerações feitas pelo RDH 2006, que contrariam a racionalidade privativista da política de água e do saneamento ambiental foram baseadas nas principais teses consensuais entre os países membros da ONU, que firmaram compromissos com a declaração Universal de Direitos Humanos, com a Agenda - 21 (para o desenvolvimento sustentável) e os Objetivos do Milênio, que deveriam ser retomadas nos compromissos a serem assumidos pela Rio+20.

No entanto, constata-se uma renitente situação, quer social ou política, na maioria dos países com baixo indicador de desenvolvimento humano (IDH), embora alguns, como o Brasil, apresentem, paradoxalmente, posição de vantagem econômica a nível mundial, quando mensurado pelo Produto Interno Bruto (PIB). O Brasil é considerado hoje uma potencia econômica (6 $6^{\mathrm{a}}$ posição mundial), porém apresenta um IDH médio de 0,718 , conforme o Relatório do Desenvolvimento Humano 2011, divulgado pelo Programa das Nações Unidas para o Desenvolvimento - PNUD $^{16}$. Ficou classificado na $84^{\text {a }}$ posição entre os 187 países avaliados pelo índice, em 2011. O IDH é usado como referência da qualidade de vida e desenvolvimento, quanto mais próximo do valor 0 , piores as condições sociais ${ }^{17}$.

No Quadro 2 apresentamos diversas outras constatações feitas no RDH (2006). O relatório torna evidente o conflito de interesses na crise da água e do saneamento no nível internacional e que se refletem negativamente nos países com precário IDH. Chama a atenção para o fato de que a exclusão ao acesso à água e ao saneamento continua fora das prioridades que afetam mais as populações pobres do planeta. Os países que alcançaram elevada condição e desenvolvimento têm situação adequada de acesso à água e ao saneamento ambiental e, portanto, não incluindo mais estas questões em suas agendas, enfraquecem as redes de solidariedade frente aqueles ainda com carências e precariedades nesses setores, o que é um grave erro, uma vez que a globalização faz fluir sem fronteiras também as misérias humanas e as doenças por elas carreadas.

A proteção dos mananciais de água potável hoje requer como nunca a proteção contra os dejetos industriais e da agricultura químico-dependente, uma contingência dos tempos pós II Guerra Mundial, e que estão implicados com o padrão de produção e de consumo que compõe não só a crise das águas, mas a crise ambiental e a crise civilizatória de nossa contemporaneidade.

\section{Políticas de universalização de acesso à água e suas contradições}

No Brasil, o valor universal de acesso á água é um princípio da Lei $11.445 / 2007^{18}$ (trata do Saneamento Básico), que implica em uma responsabilização do Estado, e dos operadores dos serviços pelo atendimento adequado de água a toda 
Quadro 1. Síntese das considerações sobre o Relatório de Desenvolvimento Humano (RDH) de 2006.

\begin{tabular}{|c|c|}
\hline Considerações & Pontos de reflexão \\
\hline $\begin{array}{l}\text { Apesar do desenvolvimento tecnológico e da } \\
\text { globalização, hoje ainda morrem mais crianças } \\
\text { devido à falta de água potável e de instalações } \\
\text { sanitárias do que por qualquer outra causa. }\end{array}$ & $\begin{array}{l}\text { Paradoxo que evidencia que mortes evitáveis de } \\
\text { crianças mediante políticas de saneamento ambiental } \\
\text { não estão sendo resolvidas pelo desenvolvimento } \\
\text { tecnológico e globalização. }\end{array}$ \\
\hline $\begin{array}{l}\text { A exclusão do acesso à água potável e ao } \\
\text { saneamento ambiental destrói mais vidas } \\
\text { humanas do que qualquer conflito ou violência } \\
\text { por armas de fogo e bélicas. }\end{array}$ & $\begin{array}{l}\text { A violência decorrente de conflitos armados tem } \\
\text { muito maior visibilidade midiática do que a quantidade } \\
\text { de mortes de seres humanos pela falta de acesso a água } \\
\text { potável e saneamento ambiental. }\end{array}$ \\
\hline $\begin{array}{l}\text { Essa exclusão também acentua as profundas } \\
\text { desigualdades em termos de oportunidades de } \\
\text { vida que separam os países e as suas populações, } \\
\text { em diversos tipos carência que se refletem na } \\
\text { saúde, nas vulnerabilidades de gênero, } \\
\text { geracional, étnicas, sociais, culturais e } \\
\text { econômicas. }\end{array}$ & $\begin{array}{l}\text { Nenhuma política que pretenda atuar nos problemas } \\
\text { de saúde e nas vulnerabilidades econômicas, sociais, } \\
\text { culturais, de gênero, geracional e étnicas, que } \\
\text { evidenciam desigualdades sociais, poderá ser efetiva se } \\
\text { não enfrentar a exclusão do acesso à água, mediante a } \\
\text { aplicação do princípio da equidade e da precaução. }\end{array}$ \\
\hline $\begin{array}{l}\text { A falta de acesso à água e ao saneamento } \\
\text { ambiental a nível mundial, além de provocar } \\
\text { perdas de vidas e sofrimentos humanos } \\
\text { compromete o desenvolvimento de modo } \\
\text { global e onera importantes recursos públicos } \\
\text { com agravos evitáveis à saúde. }\end{array}$ & $\begin{array}{l}\text { Os custos com agravos à saúde decorrentes da escassez } \\
\text { de água e de saneamento ambiental deveriam ser } \\
\text { internalizados e aplicados como indicadores negativos } \\
\text { na avaliação do modelo de desenvolvimento. O } \\
\text { retorno para a sociedade, economizando recursos } \\
\text { financeiros necessários ao desenvolvimento de } \\
\text { políticas sociais e de infraestrutura deve ser valorizado, } \\
\text { aqui também é uma aplicação do princípio da } \\
\text { precaução e da equidade social. }\end{array}$ \\
\hline $\begin{array}{l}\text { Por estas razões e do ponto de vista dos direitos } \\
\text { humanos, da justiça social e ambiental os danos } \\
\text { infligidos pela exclusão de acesso a água e ao } \\
\text { saneamento ambiental são insustentáveis. }\end{array}$ & $\begin{array}{l}\text { As metas estabelecidas pela Agenda } 21 \text { e pelos } \\
\text { objetivos do milênio (ODM) no país só poderão ser } \\
\text { alcançadas mediante políticas públicas que priorizem } \\
\text { acesso à água e ao saneamento ambiental, uma } \\
\text { aplicação do princípio de responsabilidade. }\end{array}$ \\
\hline $\begin{array}{l}\text { A solução para a exclusão ao acesso à água e ao } \\
\text { saneamento ambiental, além de uma questão } \\
\text { moral e um ato de justiça, traz benefícios para } \\
\text { toda a Humanidade nas mais diversas } \\
\text { dimensões de sua vida em sociedade e no } \\
\text { equilíbrio dos ecossistemas. Um melhor acesso } \\
\text { à água e ao saneamento funciona como agente } \\
\text { catalisador de um avanço gigantesco em termos } \\
\text { de desenvolvimento humano, proporcionando } \\
\text { benefícios a saúde pública, educação e ao } \\
\text { crescimento econômico. }\end{array}$ & $\begin{array}{l}\text { A solução local para enfrentar a exclusão ao acesso à } \\
\text { água e ao saneamento tem repercussões de ordem mais } \\
\text { global tanto para a sociedade, como para os } \\
\text { ecossistemas. Um exemplo da aplicação do princípio } \\
\text { do pensar globalmente e agir localmente. }\end{array}$ \\
\hline $\begin{array}{l}\text { O que falta é a vontade política e a visão } \\
\text { necessárias para aplicar recursos em prol do } \\
\text { bem comum. O progresso dos países ricos foi } \\
\text { possível graças a um novo contrato social entre } \\
\text { governos e população - um contrato baseado } \\
\text { na ideia da cidadania comum e no } \\
\text { reconhecimento das responsabilidades } \\
\text { governamentais. }\end{array}$ & $\begin{array}{l}\text { Um pacto social pela cidadania não pode ser figura de } \\
\text { retórica, precisa de fato ações firmes de } \\
\text { responsabilidade governamental com valores } \\
\text { republicanos e democráticos que efetivem políticas } \\
\text { públicas de interesse social. Rever o Plano de } \\
\text { Aceleração do Crescimento a luz de compromissos } \\
\text { com a sustentabilidade do desenvolvimento humano. }\end{array}$ \\
\hline
\end{tabular}

Fonte: PNUD $^{14}$, ajustada e complementada por reflexões dos autores. 
Quadro 2. Constatações do Relatório de Desenvolvimento Humano-2006 sobre a crise da água e do saneamento básico.

\begin{tabular}{l} 
Constatações \\
\hline 1. Fraca tomada de consciência da gravidade do problema; \\
2. Esforço insuficiente desenvolvido pelos governos nacionais e pela comunidade internacional para \\
acabarem com a pobreza e as desigualdades que perpetuam a crise; \\
3. A crise da água e do saneamento básico é, sobretudo, uma crise dos pobres em geral e das mulheres \\
em particular, que são segmentos com baixa capacidade organizativa e reivindicatória na definição das \\
prioridades nacionais; \\
4. A água e o saneamento também são os parentes pobres da cooperação para o desenvolvimento \\
internacional; \\
5. A mesma comunidade internacional que se mobilizou de forma impressionante, para preparar a \\
resposta a uma potencial ameaça resultante da epidemia de gripe aviária, finge não ver a epidemia real \\
que aflige todos os dias centenas de milhões de pessoas; \\
6.A crise da água e do saneamento básico com que se defrontam as famílias pobres no mundo em \\
desenvolvimento encontra paralelo com os primórdios da história dos países ricos da atualidade; \\
7. No mundo industrial poucos são aqueles capazes de refletir acerca da enorme importância que a água \\
potável e o saneamento básico tiveram na evolução de seus próprios países. Mas sabe-se que o que mais \\
contribuiu para essa mudança foi a separação entre as águas para consumo e os dejetos humanos.
\end{tabular}

Fonte: PNUD ${ }^{14}$, ajustada pelos autores.

a população do território sobre o qual têm responsabilidade. A promoção do acesso universal requer um conjunto de ações, desde a preservação dos mananciais, a prioridade de acesso destes para o consumo humano, bem como a produção de água potável e sua distribuição. A qualidade da água do manancial, sua vazão e a densidade populacional são fatores que determinam condições de acesso. De modo geral, os serviços se eximem dessa responsabilidade, restringindoa apenas aos consumidores de seu sistema.

Populações que vivem em áreas de baixa densidade, como as rurais ou mesmo urbanas, mas com características rurais podem ter soluções individuais de acesso à água como uma forma adequada de acesso. Para populações em áreas urbanas adensadas a solução deve ser coletiva. Em ambas as situações o acesso não está apenas relacionado à ideia de se ter ou não o abastecimento de água, mas sua adequação em termos de qualidade e quantidade. E esta adequação implica não apenas aspectos sanitários, mas também de direito à manutenção da vida com qualidade.

$\mathrm{O}$ direito a todas as pessoas do acesso adequado à água está, portanto, relacionado às condições de obtenção dessa água, à sua qualidade e quantidade, no percurso dos mananciais aos domicílios. Um olhar que se estende das bacias hidrográficas às condições de habitabilidade, que requer preservação e recuperação dos recursos hídricos e reconhecimento das condições em que estas acessam a água nos domicílios.
A partir da década de 1990 e, sobretudo na de 2000, na Europa, EUA, África e América Latina, tem ocorrido mobilizações contrárias às privatizações desses serviços de água, omo os de Grenoble, Paris, Munique, Stuttgard, Berlim, Cochabamba, Buenos Aires, Montevidéu, Nairóbi, Johanesburgo e outros, os quais foram reestatizados ${ }^{19}$.

Práticas perversas de gestão das empresas prestadoras de serviços privatizados, superdimensionam os custos operacionais para justificar o aumento de tarifas. E promovem redução de custos, para maximização de lucros, reduzem número de funcionários, comprometendo a qualidade da manutenção, sobretudo a preventiva ${ }^{9}$.

Os principais motivos para a reivindicação do caráter público desses serviços são: elevação das tarifas acima das taxas de lucro previstas; precarização de sistemas, tornando-os mais vulneráveis; ampliação dos sistemas em áreas de maior retorno econômico, excluindo populações vulneráveis que trariam menor arrecadação tarifária, afetando a qualidade de vida e a sustentabilidade ambiental. A exemplo da empresa que operava em Buenos Aires, que demitiu 4.660 trabalhadores (52\% do efetivo $)^{9}$. As violações ambientais decorrentes de vazamento de água e o despejo clandestino de esgotos são recorrentes ${ }^{9} \mathrm{e}$ do uso intensivo de cloro no tratamento são externalidades não incorporadas ao sistema de produção de água para abastecimento.

Um indicador de benefício da re-estatização dos serviços de água, como os exemplos de $\mathrm{Mu}$ - 
nique e Paris, é a proteção ambiental de áreas de recarga de aquíferos. Nestes casos, esses serviços promoveram o desenvolvimento de agricultura orgânica, inclusive subsidiando diretamente pequenos produtores, com a finalidade de redução de nitratos nas águas ${ }^{19}$.

\section{Desafios para a gestão de recursos hídricos no contexto de conflitos dos usos múltiplos da água}

A Política Nacional de Recursos Hídricos PNRH foi instituída em 1997 pela Lei 9.433 que criou o Sistema Nacional de Gerenciamento dos Recursos Hídricos ${ }^{20}$. Essa Lei substituiu o Código de Águas de 1934, que já era conceitualmente bastante avançado para a época. No entanto, a despeito do arcabouço jurídico existente, persiste a falta de planejamento dos recursos hídricos no Brasil. O crescimento populacional, a industrialização e o processo de urbanização intensivo das últimas décadas pressionaram a reformulação normativa do setor no país. Vale destacar entre as mudanças a incorporação por parte da união dos recursos hídricos, tornando-os públicos, requerendo a outorga para exploração. A criação dos comitês de bacia, descentralizando, e incorporando a sociedade civil na gestão dos recursos hídricos foi também um importante avanço para a intenção de democratização e de enfrentamento dos conflitos de interesses para os múltiplos usos das águas.

A cobrança pelo uso da água foi outro fator importante, agindo como um indutor na sua economia e na prevenção de desperdícios. Outro aspecto da política de gerenciamento, ligado à questão da qualidade da água, foi o princípio do poluidor pagador, entendido como uma medida responsabilizadora pela contaminação de mananciais, podendo ser considerada uma medida indutora, principalmente do necessário tratamento de efluentes oriundos de processos produtivos ${ }^{20}$.

A baixa preocupação com a qualidade da água é uma questão crítica permanente, houve um retrocesso em relação ao velho Código de Águas, que era mais rigoroso do que a atual legislação. Ao admitir o "uso múltiplo" das águas dos mananciais atuou como um incentivador do aproveitamento ou exploração máxima das bacias hidrográficas, o que é incompatível com a necessidade prioritária para o consumo humano. Da forma que está exposta, o uso para o consumo humano é colocado no mesmo plano de igualdade dos demais usos, diferentemente do Código de Águas, que o definia como o mais nobre dos usos.
O crescimento populacional e a disponibilidade de água são inversamente proporcionais, assim, o aproveitamento máximo da bacia pela diversidade dos usos pode ser um fator de elevado risco de perda da qualidade da água para o consumo humano, que não conta com tecnologia factível de tratamento para grandes sistemas, restringindo-se apenas aos aspectos físicos, seguido de desinfecção e não eliminando os contaminantes químicos a exemplo de metais, hormônios e agrotóxicos ${ }^{20}$.

O uso e a ocupação do solo, assim como também a proteção do manancial são elementos importantes para serem considerados na qualidade final da água das bacias. A admissão do uso múltiplo das bacias hidrográficas de mananciais importantes para o consumo humano se apresenta como indesejável na garantia da qualidade das águas.

Determinados tipos de assentamentos humanos ou atividades produtivas em áreas de manancial pressionam negativamente a qualidade da água para o consumo humano. As estações de tratamento de água disponíveis no Brasil são dimensionadas para prevenir a transmissão de doenças infecto-parasitárias, ainda presas a situação epidemiológica do começo do século XX e não incorpora o crescente risco de intoxicações químicas (agudas e crônicas) iniciado após a Segunda Guerra Mundial.

A gravidade da situação levou a partir década de 1980, alguns Estados a tomarem iniciativas de proteção de mananciais para consumo humano, a exemplo de Pernambuco ${ }^{21}$. Esse Estado promulgou a Lei no 9.860 , de 12 de agosto de $1986^{21}$, e posteriormente veio a Lei 9.433 de $1997^{20}$. Esse ordenamento jurídico do uso e da ocupação do solo nas bacias de contribuição dos mananciais de interesse para o consumo humano foi restrito a área da Região Metropolitana do Recife, onde se situam dois grandes aquíferos: o de Beberibe e o de Barreiras.

Supomos que a legislação restrita a esse território foi um reflexo da condição hídrica do estado e dos problemas de escassez. Pernambuco apresentava a pior situação do Brasil, com $2 / 3$ do seu território situado no semi-árido.

Essa legislação delimitou as áreas dentro das bacias de contribuição dos mananciais em função do risco e da proximidade do manancial e um ordenamento das atividades possíveis de assentamento e aquelas não permitidas. Como exemplo, não é permitido o uso de agrotóxicos e de fertilizantes; o lançamento ou disposição de resíduos sólidos; e as construções residenciais 
deverão ter seus projetos de destino final de esgoto aprovados previamente; o assentamento na área ficou mais restritivo, só permitindo atividade econômica para agricultura e aquicultura de pequena escala ${ }^{21}$.

O fato da Lei no $9.860 / 86^{21}$ ter ficado restrita a Região Metropolitana do Recife foi uma grande perda de oportunidade de o estado ter protegido os mananciais de outras áreas, especialmente aquelas mais vulneráveis, considerando que 70\% do seu território se encontram no semi-árido e que requerem maior atenção, frente a disponibilidade de água ser bem menor do que a da Região Metropolitana e da Zona da Mata deste Estado.

Outra questão de grande importância para a gestão é a separação político-administrativa que trata a água por divisão: água natural ou bruta; água potável ou para consumo humano, e águas minerais. A gestão da água é separada administrativamente com sistemas de informações separados para cada uma dessas tipologias. A água natural ou bruta é gerida e legislada pelos órgãos ambientais e de recursos hídricos; a água potável é gerida pelas concessionárias de abastecimento cuja concessão é dada pelo município, e a qualidade da água natural fica inserida no próprio setor que a gerencia, ou seja, de recursos hídricos. $\mathrm{Na}$ água potável a sua qualidade é gerida pela concessionária e sua fiscalização no setor saúde. A gestão setorizada da água é realizada mediante fronteiras político-administrativa estanques sem uma perspectiva de gestão integrada ${ }^{22}$.

A qualidade da água começa na sua origem, no uso e ocupação do solo da bacia de contribuição e nas medidas de proteção dos mananciais. A estação de tratamento é apenas um equipamento para turbidez, corrigir o $\mathrm{pH}$ e a cor e, quando necessário, a desinfecção da água a ser consumida pela população, nada mais. Sabe-se que grandes acidentes com água potável tiveram sua origem no manancial e não no sistema de abastecimento, a exemplo da tragédia da hemodiálise de Caruaru-PE.

O relato deste caso ilustra como a água tem sido mal gerida pela desarticulação entre os órgãos gestores. Um caso emblemático de dicotomia 'qualidade x quantidade' e de insustentabilidade.

Apesar de ter ocorrido no ano de 1996, e ter sido um enorme trauma para a população, de lá pra cá pouca coisa mudou e os avanços ainda são poucos em termos de Brasil, ficando as melhores iniciativas restritas a regiões sul e sudeste do país ${ }^{8}$.

Quando ocorreu a morte de 71 pessoas em Caruaru por conta de contaminação de água uti- lizada em tratamento hemodiálico já havia uma legislação de diversos setores: de recursos hídricos, ambiental e de saúde. O Quadro 3 apresenta a legislação em vigor no período dessa tragédia agregada segundo seus objetivo, por nível de governo e setor: (1) ambiente (meio ambiente e recursos hídricos) e (2) saúde ${ }^{8}$.

Observa-se que das quatro legislações estaduais, duas são para criação de empresas (Lei Estadual no 6.307 de 29/07/1971 ${ }^{23}$ e a Lei Estadual n. ${ }^{\circ} 7.267$ de $16 / 12 / 1976^{24}$ ), a primeira na área de saneamento e a segunda na de meio ambiente, delimitando o objetivo de cada uma e a forma de atuação.

A primeira cria a Companhia Estadual de Saneamento - Compesa, que passa a ser a executora da política de saneamento em Pernambuco e a concessionária estadual dos serviços de abastecimento de água e esgotamento sanitário sendo vinculada na época à Secretaria Estadual de Recursos Hídricos.

A segunda cria a Companhia Estadual de Meio Ambiente - CPRH, com objetivos, de controlar a qualidade do meio ambiente, a administração e o desenvolvimento dos recursos hídricos e o controle de qualidade de água das bacias hidrográficas dos rios estaduais, principalmente dos mananciais destinados ao abastecimento público de água.

O Decreto Estadual n ${ }^{\circ} .18 .251$ de 21/12/1994 ${ }^{25}$ regula os serviços de abastecimento de água e coleta de esgoto da empresa estadual de saneamento $^{23}$. Essa legislação apresenta obrigações com a concessão, como, na operação dos sistemas, as obrigações do usuário e da concessionária e apresenta a política tarifária da empresa.

A Lei no 9.860 de 12/08/1986 ${ }^{21}$, cuja publicação ocorreu dez anos antes tragédia de Caruaru, regula a proteção dos mananciais de interesse para o abastecimento de água na Região Metropolitana do Recife e a forma de ocupação do solo de suas bacias hidrográficas. O grande mérito dessa legislação foi o ordenamento da ocupação do solo nas bacias hidrográficas dos mananciais superficiais e subterrâneos, de uso atual ou futuro para abastecimento na Região Metropolitana do Recife e o seu demérito foi justamente a restritação de su aplicação, como já exposto.

Das seis legislações federais apresentadas no quadro, três são do setor meio ambiente; uma de regulamentação de concessão de empresas públicas; e duas do setor saúde.

Para o de meio ambiente, a mais antiga, Lei n. ${ }^{\circ} 4.771$ de 15/09/1965 ou também denominada como Código Florestal ${ }^{26}$, trata das florestas na- 
Quadro 3. Legislação em vigor no ano de 1996, para as áreas de saúde, meio ambiente, recursos hídricos e

\begin{tabular}{|c|c|c|c|}
\hline Legislação & Setor & Nível de governo & Objetivos \\
\hline Lei n.o 4.771 de 15/09/1965 & Meio Ambiente & Federal & Código Florestal \\
\hline Lei no 6.307 de 29/7/1971. & Saneamento & Estadual & $\begin{array}{l}\text { Cria a Companhia Pernambucana } \\
\text { de Saneamento - Compesa }\end{array}$ \\
\hline Lei n.o 7.267 de 16/12/1976 & Meio Ambiente & Estadual & $\begin{array}{l}\text { Cria a Companhia Estadual de } \\
\text { Meio Ambiente - CPRH }\end{array}$ \\
\hline Lei n.o 6.938 de $31 / 08 / 1981$ & Meio Ambiente & Federal & $\begin{array}{l}\text { Dispõe sobre a Política Nacional de } \\
\text { Meio Ambiente }\end{array}$ \\
\hline $\begin{array}{l}\text { Resolução no } 20 \text { do } \\
\text { Conama } 18 / 06 / 1986\end{array}$ & Meio Ambiente & Federal & $\begin{array}{l}\text { Classificação das águas, doces, } \\
\text { salobras e salinas do Território } \\
\text { Nacional }\end{array}$ \\
\hline Lei no 9.860 de $12 / 08 / 1986$ & Meio Ambiente & Estadual & $\begin{array}{l}\text { Delimita as áreas de proteção dos } \\
\text { mananciais de interesse da Região } \\
\text { Metropolitana do Recife, e } \\
\text { estabelece condições para a } \\
\text { preservação dos recursos hídricos }\end{array}$ \\
\hline $\begin{array}{l}\text { Portaria GM no } 36 \\
\text { de } 19 / 01 / 1990\end{array}$ & Saúde & Federal & $\begin{array}{l}\text { Qualidade de água para o consumo } \\
\text { humano }\end{array}$ \\
\hline $\begin{array}{l}\text { Decreto Estadual no } 18.251 \\
\text { de } 21 / 12 / 1994 \text {. }\end{array}$ & Saneamento & Estadual & $\begin{array}{l}\text { Aprova o regulamento de } \\
\text { fornecimento de água e coleta de } \\
\text { esgoto da Compesa }\end{array}$ \\
\hline Lei n.o 8.987 de $13 / 02 / 1995$ & Saneamento & Federal & $\begin{array}{l}\text { Regulamenta as Concessões de } \\
\text { serviços públicos }\end{array}$ \\
\hline
\end{tabular}

Fonte: Castro e Scariot ${ }^{8}$

cionais e outros tipos de vegetação, define as áreas de preservação permanente, dentre elas a proteção das matas ciliares. Definida como a vegetação em torno dos corpos hídricos, rios, nascentes, lagoas, lagos e reservatórios de águas artificiais (açudes). Os reservatórios artificiais, nesta situação têm como obrigatória, a desapropriação ou aquisição pelo empreendedor das áreas de preservação permanente do seu entorno.

As outras duas legislações federais que tratam do meu ambiente são a Lei n. ${ }^{\circ} 6.938$ de 31/ 08/1981 ${ }^{27}$ e a Resolução n ${ }^{\circ} 20$ de 18/06/1986 ${ }^{28}$ do Conama (Conselho Nacional do Meio Ambiente, que é o órgão consultivo e deliberativo do Sistema Nacional de Meio Ambiente). A primeira trata da Política Nacional de Meio Ambiente ${ }^{27}$, promulgada logo após a constituição de 1980. Essa legislação renova na medida que incorpora o conceito do desenvolvimento sustentável, com compartilhamento entre desenvolvimento e preservação ambiental, além de incorporar novos principios como o do equilibrio ecológico, uso racional do solo, água e ar e proteção de ecossistemas e controle de atividades poluidoras.

A segunda a Resolução no 20 do Conama trata da qualidade da água do ambiente natural, doces, salgadas e salobras ${ }^{28}$. Essa legislação é importante pela classificação que ela atribui aos mananciais superficiais, em função da qualidade de suas águas. Em função dessa qualidade, são atribuídos tipos de usos adequados para elas, que podem ser para o consumo humano, recreação, dessedentação de animais, geração de energia e outros usos mais, como a irrigação e a navegação.

Todo esse aparato legal não foi suficiente para evitar aquela tragédia. Ter a legislação não é suficiente para a proteção dos mananciais. Se ela não é cumprida e se os órgãos públicos não execu- 
tam seu papel, haverá sérios problemas de saúde pública.

Na região de Caruaru, nenhum plano de contingência foi elaborado pelo poder público para fazer frente à seca que estava em curso desde 1991 comprometendo profundamente o sistema de abastecimento de água. Em 1996, a intermitência ocorria com intervalos de dez dias sem água. A empresa concessionária distribuía água a determinados setores da saúde mediante caminhão pipa, com o agravante de captar água do decantador da estação de tratamento. Erro fatal. Mas a culpa ficou para a natureza, as algas Cianofíceas, e nada mais foi investigado ${ }^{8}$.

Esse triste caso, com tantas vítimas, retrata entre outras vulnerabilidades, a falta de intersetorialidade no que tange a gestão da água e sua descontextualização. Durante toda a investigação das mortes por intoxicação por algas Cianofíceas os órgãos ambientais permaneceram omissos, apenas o da saúde tentou dar resposta e sofreu alguma responsabilização ${ }^{29}$, embora no final das contas as vítimas e suas famílias ficaram sem os devidos reparos pelos danos sofridos.

A lição desse caso aponta para a necessidade de um modelo de gestão intersetorial para a água com a participação da sociedade civil organizada, das concessionárias de saneamento, com a participação do setor saúde e com um sistema de in- formação único e aberto. Só dessa forma poderemos encarar os novos desafios que estão por vir, a exemplo do aquecimento global, o crescimento populacional e econômico. A disponibilidade de água e sua qualidade estão em níveis críticos como já demonstrado pelo relatório $\mathrm{RDH} / \mathrm{PNUD}^{15}$.

Ultrapassar o modelo economicista de tratar a água como uma commodity; adotar um modelo universal, público e integrado para garantia de acesso e de qualidade da água; trazer para a gestão a responsabilidade de Estado, considerando a água como um direito humano inalienável são as perspectiva que apontamos para a superação da crise ${ }^{30}$.

\section{Colaboradores}

LGS Augusto e AM Costa trabalharam na concepção e na redação final; IGD Gurgel trabalhou na revisão crítica; e, HF Câmara Neto e CH Melo trabalharam na redação final.

\section{Referências}

1. Rattner H. O desafio da água. Associação Brasileira para o Desenvolvimento de Lideranças. [acessado 2012 abr 02]. Disponível em: http://www.abdl.org.br/ article/articleview/4170/1/97/

2. Pontes CAA, Schramm FR. Bioética da proteção e papel do Estado: problemas morais no acesso desigual à água potável. Cad Saude Pub 2004; 20(5):13191327.

3. Silva ER. O curso da água na história: simbologia moralidade e a gestão de recursos hídricos [tese]. Rio de Janeiro (RJ): Escola Nacional de Saúde Pública; 1998.

4. Câmara HF. A "Tragédia da Hemodiálise" 12 anos depois: poderia ter sido evitada? [tese]. Recife (PE): Centro de Pesquisa Aggeu Magalhães; 2009.

5. Ferreira MR, Rebelo Júnior M. As Oligarquias da água e a mercantilização da água doce: um processo de conquistas do capital. Economia \& Pesquisa 2007; 1(1):54-77.
6. United Nations Water. Statistics, graphs and maps water and climate change. [acessado 2012 abr 01]. Disponível em: http://www.unwater.org/statistics_ clim.html

7. Conferência das Nações Unidas sobre Meio Ambiente e Desenvolvimento. A Agenda 21. Brasília: Senado Federal; 1996.

8. Castro CFA, Scariot A. Escassez de água cria nova injustiça: a exclusão hídrica. [acessado 2012 fev 29]. Disponível em: http://www.pnud.org.br/gerapdf. php?id01=1067

9. Barlow M, Clarke T. Ouro azul: como as grandes corporações estão se apoderando da água doce do nosso planeta. São Paulo: M. Books; 2003.

10. Brasil. Anvisa. Resolução 309/1999. Diário Oficial da União 1999; 19 jul.

11. World Health Organization (WHO). Right to water. Genebra: WHO Library; 2003. 
12. Barlow M. World Water Forum paves the way to privatize nature, undermine Human Rights to Water in Rio+20. [acessado 2012 abr 01]. Disponível em: http://canadians.org/blog/?p=14178

13. Universidade Federal Fluminense. Relatora da ONU alerta que água e saneamento devem manterem-se direitos humanos. [acessado 2012 abr 02]. Disponível em: http://www.uff.br/emdialogo/node/3031

14. United Nations Educational, Scientific and Cultural Organization (UNESCO). The United Nations World Water Development Report, WWDR. [acessado 2012 abr 01]. Disponível em: http://www.unesco.org/new/ en/natural-sciences/environment/water/wwap/wwdr

15. Programa das Nações Unidas para o Desenvolvimento (PNUD). Relatório do Desenvolvimento $\mathrm{Hu}$ mano 2006 - A água para lá da escassez: poder, pobreza e a crise mundial da água. [acessado 2012 abr 02]; [cerca de 422p.]. Disponível em: http://hdr.undp. org/en/reports/global/hdr2006/chapters/portuguese/

16. Programa das Nações Unidas para o Desenvolvimento (PNUD). Relatório de Desenvolvimento Humano 2011: Sustentabilidade e equidade: Um futuro melhor para todos. [acessado 2012 abr 02]; [cerca de 183p.]. Disponível em: http://hdr.undp.org/en/reports/global/ hdr2011/download/pt/).

17. G1/Globo. Brasil ocupa $84^{a}$ posição entre 184 países. [acessado 2012 abr 02]. Disponível em: http:// g1.globo.com/brasil/noticia/2011/11/brasil-ocupa84-posicao-entre-187-paises-no-idh-2011.html

18. Brasil. Lei 11.445 de 5 de janeiro de 2007. Estabelece diretrizes nacionais para o saneamento básico; altera as Leis nos 6.766, de 19 de dezembro de 1979, 8.036, de 11 de maio de 1990, 8.666, de 21 de junho de 1993, 8.987, de 13 de fevereiro de 1995; revoga a Lei no 6.528, de 11 de maio de 1978; e dá outras providências. Diário Oficial da União 2007; 11 jan.

19. Water Makes Money. Como as multinacionais transformam a água em dinheiro. [Vídeo documentário]. Paris: Kern Kilmproduktion GmbH; 2010. Disponível em: http://www.watermakesmoney.org.

20. Brasil. Lei $n^{\circ} 9.433$ de 8 de janeiro de 1997. Institui a Política Nacional de Recursos Hídricos, cria o Sistema Nacional de Gerenciamento de Recursos Hídricos, regulamenta o inciso XIX do art. 21 da Constituição Federal, e altera o art. $1^{\circ}$ da Lei no 8.001, de 13 de março de 1990, que modificou a Lei $\mathrm{n}^{\circ} 7.990$, de 28 de dezembro de 1989. Diário Oficial da União 1997; 9 jan.

21. Pernambuco. Lei no 9.860, de 12 de agosto de 1986. Delimita as áreas de proteção dos mananciais de interesse da Região Metropolitana do Recife, e estabelece condições para a preservação dos recursos hídricos. [acessado 2008 jun 15]. Disponível em: http:/ /www.cprh.pe.gov.br/downloads/lei9860n1.doc

22. Muñoz HR, organizador. Interfaces da gestão de recursos hídricos: desafios da Lei de águas de 1997. Brasília: Secretaria de Recursos Hidricos; 2000.
23. Pernambuco. Lei Estadual no 6.307 de 29 de julho de 1971. Cria a Companhia Pernambucana de Saneamento S/A - COMPESA e autoriza o Poder Executivo Estadual a ela delegar a prestação dos serviços públicos de saneamento básico no estado. [acessado 2007 mar 15]. Disponível em: http://www.compesa .com.br/index.php?option=content $\&$ task=view \&id $=31$

24. Pernambuco. Lei Estadual n.o 7.267, de 16 de dezembro de 1976. Autoriza a constituição de uma sociedade anônima de economia mista, sob a denominação de CPRH e dá outras providências. [acessado 2007 mar 15]. Disponível em: http://www. cprh.pe.gov.br/downloads/Lei-7267.doc

25. Pernambuco. Decreto Estadual no. 18.251, de 21 dezembro de 1994. Recife, 1994. Aprovado o regulamento geral do fornecimento de água e da coleta de esgoto, realizados pela Companhia Pernambucana de Saneamento - Compesa. [acessado 2008 mar 26]. Disponível em: http://www.arpe.pe.gov.br/pdf/ audienciasaneamento/decreto_estadual_18521.pdf

26. Brasil. Lei $n^{\circ} 4.771$ de 15 setembro de 1965. Institui o novo Código Florestal. Diário Oficial da União 1965; 19 set.

27. Brasil. Lei no 6.938 de 31 de agosto de 1981. Dispõe sobre a Política Nacional do Meio Ambiente, seus fins e mecanismos de formulação e aplicação, e dá outras providências. Diário Oficial da União 1981; 02 set.

28. Brasil. Resolução Conama no 20 de 18 de junho de 1986. Classificação das águas doces, salobras e salinas de todo território nacional. Diário Oficial da União 1986; 30 jul.

29. Faria AS, Faria RC. Cenários e perspectivas para o setor de saneamento e sua interface com os recursos hídricos. Eng San Ambient 2004; 9(3):202-210.

30. Vargas MC. A ética da responsabilidade e o papel da economia na Nova Cultura da Água. In: Encontro por uma Nova Cultura da Água na América Latina; 2005; Fortaleza. Saragoza: FNCA; 2005.

Artigo apresentado em 16/04/2012

Aprovado em 23/04/2012

Versão final apresentada em 01/05/2012 